\title{
ШЕКСПИРОСФЕРА
}

DOI: $10.17805 / g g z .2017 .5 .9$

\section{Шекспир в кино: национальное и глобальное*}

\author{
Б. Н. ГАЙДИН \\ МОСКОВСКИЙ ГУМАНИТАРНЫЙ УНИВЕРСИТЕТ
}

В статье рассматривается специфика влияния творчества У. Шекспира на современный кинематограф на примере двух художественных фильмов («Мой личный штат Айдахо» Гаса Ван Сента и «Изображая жертву» К. С. Серебренникова). Автор затрагивает проблему определения понятия «мировое кино» и анализирует характер соединения национального и глобального в “шекспировском кино». Отмечается, что шекспировское наследие может проявляться в кинематографе не только в диалоге режиссера с Шекспиром, но и в полилоге с другими режиссерами, писателями, исследователями, деятелями культуры и искусства, которые внесли свой вклад в национальные традиции рецепции сочинений британского драматурга и поэта. Различные отсылки к Шекспиру, по мнению автора, могут использоваться для подчеркивания наднационального характера проблематики, затрагиваемой режиссерами в своих кинокартинах.

Ключевые слова: У. Шекспир; шекспиросфера; Шекспир в современном кино; современный кинематограф; мировое кино; «Мой личный штат Айдахо»; Гас Ван Сент; «Изображая жертву»; К. С. Серебренников

\section{Shakespeare on Film: The National and Global}

\author{
B. N. GAYDIN \\ MOSCOW UNIVERSITY FOR THE HUMANITIES
}

The article considers the characteristics of the influence of W. Shakespeare's works on contemporary cinematography in the cases of two feature films ("My Own Private Idaho" directed by Gus Van Sant and "Playing the Victim" directed by Kirill Serebrennikov). The author touches upon the issue of the definition of the concept "world cinema" and analyzes the features of the combination of the national and global in "Shakespearean cinema". It is noted that Shakespeare's legacy appears in cinematography not only in the director's dialogue with Shakespeare but also in the polylogue with other auteurs, writers, scholars, cultural figures and people of art who have made their contribution to national traditions of the reception of the works by the British playwright and poet. Various references to Shakespeare, in the author's view, can be used to emphasize the supranational character of the issues that directors address in their movies.

Keywords: W. Shakespeare; Shakespearean sphere; Shakespeare in contemporary cinema; contemporary cinematography; world cinema; "My Own Private Idaho"; Gus Van Sant; "Playing the Victim"; Kirill Serebrennikov

* Статья подготовлена в рамках проекта «Шекспир в современной русской культуре: национальное и глобальное», осуществляемого при поддержке Совета по грантам Президента РФ (MK-1182.2017.6).

The article was prepared within the framework of the project "Shakespeare in Contemporary Russian Culture: The National and Global" with support from the Council for Grants of the President of Russian Federation (MK-1182.2017.6). 


\section{ВВЕАЕНИЕ}

Влияние творчества У. Шекспира на мировой кинематограф сложно переоценить. Кинорежиссеры разных стран и национальностей, принадлежащие к самым разным направлениям и школам, работающие в различных жанрах и эстетиках, неустанно обращаются к его пьесам, поэмам и сонетам, переосмысливают их содержание, пользуясь широким спектром возможностей, которые открывает перед ними мир современного киноискусства.

Как известно, Шекспир считается наиболее популярным драматургом в мире. Согласно Книге рекордов Гиннесса 2017 г. за последние четыре столетия его книги разошлись по миру тиражом свыше 4 млрд экземпляров (Guinness World Records 2017, 2016: 176). Также ни одному другому литератору пока не удалось побить мировой рекорд Шекспира как автора, по произведениям которого снято самое большое количество фильмов за всю историю кинематографа. В 2014 г., когда весь мир праздновал 450-летие со дня рождения драматурга, были известны как минимум 420 полнометражных художественных фильмов и телефильмов, снятых по произведениям драматурга (Lynch, 2014: Электронный ресурс; см. также: The Guinness Bookof Records 1999, 1998: 358; Pearson, 2004: 92; Nesbit, 2012). В феврале 2016 г. насчитывалось 106 киноверсий «Гамлета», 98 - «Макбета» и 64 - «Ромео и Ажульетты» (Guinness World Records 2017, 2016: 177)1․ В базе данных Internet Movie Database на 6 октября 2017 г. было 1308 упоминаний Шекспира в качестве автора (сюда входят как уже снятые фильмы, телесериалы, телеспектакли и т. п., так и еще только анонсированные проекты; William Shakespeare: Электронный ресурс). По-прежнему лидировала трагедия «Гамлет» (112 результатов; <Results for "Hamlet">: Электронный ресурс), второе место было у «Макбета» (104; $<$ Results for "Macbeth" $>$ : Электронный ресурс), замыкала тройку лидеров пьеса «Ромео и Ажульетта» (71; $<$ Results for "Romeo and Juliet" $>$ : Электронный ресурс).

Таким образом, тема «Шекспир на экране» является обширным полем для исследований. Особый интерес она представляет при изучении специфики различных национальных рецепций шекспировского наследия ( «национальные Шекспиры» - national Shakespeares; «местные / другие Шекспиры» - native / local / other Shakespeares; см., например: Dobson, 1992; Shakespeare: World Views, 1996; Shakespeare and National Culture, 1997; Orkin, 2005; World-Wide Shakespeares ... , 2005; Native Shakespeares ..., 2008), а также феномена «глобального / всемирного Шекспира» (global / universal Shakespeare; см., например: Burnett, 2007; Global Shakespeare, 2012; Huang, 2013; Shakespeare on the Global Stage ..., 2015; Thurman, 2016).

В данной статье мы проанализируем влияние творчества Шекспира на современную русскую культуру на примере кинематографа, особое внимание при этом уделяя изучению специфики рецепции шекспировского наследия во взаимосвязи национального и глобального. Объектом нашего исследования являются художественные фильмы и иные продукты визуальной культуры, рассмотренные сквозь призму национальных и глобальных социокультурных процессов. Мы ставим перед собой задачу выявить особенности национальной культуры России и ее диалога с другими культурами в данном контексте.

«МИРОВОЕ КИНО »: ПРОБАЕМА ОПРЕАЕАЕНИЯ ПОНЯТИЯ

Термин «мировое кино» (worldcinema) получил большое распространение в трудах киноведов, кинокритиков, культурологов и других исследователей, изучающих эту 
отрасль культуры. Его можно встретить практически во всех учебных курсах по истории кино. Американский теоретик кино Аадли Эндрю (Dudley Andrew) отметил, что это понятие стало подменять термин «иностранный художественный фильм» (“foreignartfilm”), который использовался в университетских курсах в 1960-х гг. (Dudley, 2004: 9; эта же работа опубликована в коллективной монографии: Dudley, 2006). Специалисты из англоязычных стран под понятием worldcinema чаще всего подразумевают кинофильмы, снятые в иной культурной и национальной традиции, чаще всего на иностранном, т. е. не на английском языке. Таким образом, к «мировому кино»в Beликобритании и США относят фильмы, незнакомые большинству жителей их стран. Некоторые исследователи идут дальше, полагая, что «мировое кино» - это любые фильмы, кроме голливудских, поскольку после окончания Первой мировой войны началось доминирование «Фабрики грез» на глобальном рынке кино (см.: Nowell-Smith, 1997: xx-xxi; Hill, 2000: xiv).

В этом случае осуществляется разграничение «своего» от «чужого», что в свою очередь ведет к субъективизации работ исследователей. В конечном итоге, на наш взгляд, получается, что любой фильм можно рассматривать как «мировое кино», поскольку, что для одного кинокритика является «иностранным», то для другого может быть «родным», и наоборот.

Иными словами, как замечают Атом Эгоян (Atom Egoyan) и Иэн Балфур (Ian Balfour) в предисловии к книге «Субтитры: об иностранности фильма», «каждый фильм является иностранным фильмом, иностранным для той или иной аудитории где-нибудь - и не только просто в языковом плане» ("Every film is a foreign film, foreign to some audience somewhere - and not simply in terms of language"; Egoyan, Balfour, 2004: 3; здесь и далее пер. наш. - Б. Г.). По их мнению, «сам статус иностранного меняется» ("...the very status of the foreign is changing"; ibid: 11). То, что раньше было «экзотикой», в ходе глобализационных процессов перестало таким являться. Однако «это не значит, что глобализация вылилась в гомогенизированный мировой кинематограф, где исчезли национальные, региональные и языковые барьеры: вовсе нет» ("It's not as if globalization has resulted in a homogenized world cinema, with national, regional, and linguistic barriers fading to white or black: far from it"; ibid).

Схожий пример - собирательный термин «музыка мира» (world music), под которым изначально понималась музыка народов мира, т. е. этническая музыка, которая возникла за пределами западноевропейской традиции. Однако в настоящее время музыковеды включают сюда и фольклорную музыку народов Западной Европы, и западноевропейскую популярную музыку с использованием «неевропейских музыкальных элементов» (Research topic ... : Электронный ресурс). Как пишет этномузыковед Филипп Болмэн (Pbilip Boblman), «старые определения и разграничения больше не имеют силы; мировая музыка может быть западной и незападной, акустической или смикшированной электронными средствами. Мир музыки мира не имеет границ, таким образом, доступ к музыке мира открыт для всех. Есть достаточные основания почти все называть музыкой мира» (“The old definitions and distinctions don't hold anymore; world music can be Western or non-Western, acoustic or electronically mixed. The world of world music has no boundaries, therefore access to world music is open to all. There's ample justification to call just about anything world music"; Bohlman, 2002: xi).

Небезынтересно сравнить термины world cinema и worl dmusic с понятием world literature (см. об этом, к примеру: Lopes, 2010). Предложенное И. В. фон Гёте в 1827 г. понятие Weltiteratur имеет три основных варианта перевода на русский язык: 
1) «мировая дитература» (совокупность абсолютно всех литературных текстов, созданных за всю историю), 2) «всеобщая литература» (литературные произведения разных народов и эпох, которые стали всеобщим культурным достоянием); 3) «всемирная литература» (произведения, которые были написаны в XIX-XXI вв., т. е. с того времени, когда в мире начал складываться единый литературный процесс). Именно третье значение и вкладывал немецкий поэт в понятие Weltliteratur (см.: $\Lambda$ уков, 2007, $2008,2009)$. Аля него «всемирная литература» - это своеобразное сообщество литераторов, каждый из которых представляет свою национальную литературу и при этом своим творчеством и контактами с другими писателями способствует укреплению взаимопонимания между народами (см.: Иванова, 2015: 61-62; Черепенникова, 2010: 100-101).

В отечественном литературоведении в общем и целом после издания в 1983-1994 гг. «Истории всемирной литературы» есть теоретико-методологическую ясность того, что представляет собой «всемирная литература» - «совокупность всех литератур мира с древнейших времен и до наших дней», которую следует рассматривать «во внутренних соотношениях и взаимосвязях ее частей, в непрестанных изменениях этих соотношений и взаимосвязей...» (Виппер, 1983: 6). Однако в западном литературоведении до сих пор нет единства мнений о том, что такое world literature. B XIX - первой половине XX века была распространена точка зрения, что в понятие «всемирная литература» входят только лучшие литературные образцы, получившие широкое, непреходящее со временем признание и носящие «наднациональный» характер (там же: 7; см. также: Неупокоева, 1978; Vipper, 1985). Таким образом, неудивительно, что как раз главным образом произведения западноевропейских авторов раньше рассматривались как основная часть «всемирной дитературы». С 1960-х гг. можно проследить тенденцию отхода теоретиков феномена «всемирной литературы», а также составителей антологий от европоцентризма².

Таким образом, если в случае с термином world literature изначально в центре исследовательских тезаурусов стояла западноевропейская традиция, то с понятиями worldmusic и worldcinema все было наоборот: эти термины возникли как раз для разграничения музыки и кинематографа стран Запада от аудио- и кинопродукции из других стран мира.

Вернемся к вопросу определения понятия «мировое кино». Кевин Муррей (Kevin Murray), поднявший эту проблему в контексте шекспировских экранизаций (Murray, 2013), отметил, что некоторые исследователи (например, Стефани Аеннисон (Stephanie Dennison), Сонг Хви Аим (Song Hwee Lim)) предпочитают говорить о том, что этот термин едва ли получит когда-нибудь четкое и обоснованное определение. $\Lambda$ юция Нагиб (Lúcia Nagib) высказала мнение, что достоинство термина в том, что он предполагает «концептуальную гибкость», которая позволяет многим использовать его в своих научных текстах без особых опасений совершить методологическую ошибку. Таким образом, многие предпочитают использовать эту модель, пытаясь актуализировать применение данного термина к предмету своих исследований (ibid: 370; см. более подробно в нашей работе: Гайдин, 2014: 46-50).

K. Муррей справедливо замечает, что исследования каких-то конкретных национальных кинематографических традиций также могут быть не дишены недостатков в теоретическом аспекте, так как и внутри национального кинематографа может быть выявлен целый ряд «подводных течений» (например, в столь сложном явлении как индийский кинематограф). Более того, рассматривая феномен кино лишь на националь- 
ном уровне, можно тем самым допустить, что государство-нация есть некое замкнутое географическое пространство, отделенное от других государств физическими границами, которые позволяют достаточно легко говорить о «формах целостности, будь то стилистических, идеологических или культурных" ("forms of cohesiveness whether stylistic, ideological, or cultural"; Murray, 2013: 371). Однако авторы целого ряда научных работ, посвященных этому вопросу, доказывают, что национальные кинематографы не могут быть чем-то неизменным и неподверженным внешнему влиянию. Сложно представить, что даже в государствах закрытого типа представители киноиндустрии вообще не обращаются к мировому опыту. В большинстве же стран в эпоху глобализации, интеграции рынков и стремительного развития сферы электронных коммуникаций говорить о специфике национального кино все сложнее, поскольку даже если съемочная группа не представляет собой интернациональную команду (а это происходит все чаще), а состоит из носителей одной национальной культуры, сложно говорить, какова была степень влияния на нее «глобального культурного котла».

Тем не менее, при всей сложности и специфике анализа современного кино глобализирующегося мира исследователи группируют фильмы с учетом так называемой национальной идентичности, авторского этоса и принципов тех или иных культурных движений и направлений, к которым апеллируют их авторы. То есть в расчет принимается «территориальное, стилистическое и идеологическое сходство» ("territorial, stylistic and ideological affinity"; ibid: 372 ) художников авторского кино.

Наше исследование влияния на отечественный кинематограф творчества Шекспира и многовековой его рецепции в различных культурах мы строим на тезисе о «равноценности» различных шекспировских адаптаций и апроприаций ${ }^{3}$. Представляется, что следует рассматривать их сквозь призму диалога различных кинематографических традиций. С нашей точки зрения, в результате можно получить новые данные, которые позволят лучше охарактеризовать современную отечественную культуру, понять ее состояние и перспективы развития.

Аалее мы разберем содержание двух художественных фильмов, режиссеры которых предложили авторские подходы к рецепции и апроприации шекспировских пьес при создании своих кинокартин: «Мой личный штат Айдахо» Г. Ван Сента (1991) и «Изображая жертву» К. С. Серебренникова (2006). Особое внимание мы уделим соотношению в них глобального и национального.

\section{«МОЙ АИЧНЫЙ ШТАТ АЙААХО»ГАСА ВАН СЕНТА}

Арама «Мой личный штат Айдахо» (тж. «Айдахо для меня одного»; My Own Private Idabo) американского режиссера Гаса Ван Сента-младшего (Gus Van Sant, Jr.), вышедшая на экраны в 1991 г., повествуют о жизни двух парней из Портленда, занимающихся бродяжничеством и проституцией. Страдающий нарколепсией 4 Майк Уотерс (Ривер Феникс / River Pboenix) и Скотт Фейвор (Киану Ривз / Keanu Reeves) peшают отправиться в путешествие в поисках матери Майка. Аействие фильма разворачивается в Сиэтле, Портленде, штате Айдахо, Риме, итальянской деревушке и снова в Портленде.

Премьера фильма состоялась на 48-м Венецианском международном кинофестивале, где Р. Феникс был награжден Кубком Вольпи за лучшую мужскую роль (La Coppa Volpi per la miglior interpretazione maschile; Annuario del cinema ... , 2010: 108). Актер также получил премию «Независимый дух» (Independent Spirit Award) за лучшую мужскую роль, а Национальное общество кинокритиков США (National Society 
of Film Critics) назвало его лучшим актером 1991 года. Картина получила положительные отклики кинокритиков, была хорошо принята зрителями, а на XVI Международном кинофестивале в Торонто получила Международную премию критиков "Шоутайм" (Showtime International Critics Award) (Allen, 2012: Электронный ресурс).

Фильм вряд ли привлек бы внимание шекспироведов, если бы в нем не было явных отсылок к историческим хроникам Шекспира: 1-й и 2-й частям «Генриха IV》 и «Генриху V», которые играют довольно значимую роль в художественной ткани фильма.

По сюжету Скотт - сын мәра Портленда, который сначала открыто бунтует против отца, пускаясь во все тяжкие, но затем после смерти ненавистного родителя внезапно кардинально меняется, получает наследство и женится. При этом он разрывает отношения с Майком и другими членами банды беспризорников, живущих в заброшенном отеле. Все этопозволяет провести параллели с шекспировским принцем Хэлом, наследником британского престола, будущим Генрихом V. В интервью режиссер отметил, что «у Скотта очень жесткий заведенный семейный порядок, который отсылает к “Генриху IV". Причина того, что принц Хэл бегает по деревням рядом с замком, заключается в том, что это его последний шанс сделать это до того, как ему придется принять ответственность, возлагаемую на короля - тоже самое происходит со Скоттом как сыном мәра...» (“In Scott's case, he has a very rigid family order which is cueing off of Henry IV. The reason Prince Hal is running around the villages around the castle is because it's his last chance to do that before he has to accept the responsibility of being king - the same with Scott as the mayor's son...”; Gus Van Sant ..., 1993).

В драме прослеживается очевидное влияние фильма «Фальстаф (Полуночные колокола)» (Falstaff (Chimes at Midnight)) Орсона Уэллса (Orson Welles; 1965). По словам режиссера Г. Ван Сента, именно работа О. Уэллса навела его на идею соединить два отдельных сценария, над которыми он начал работать еще в 1970-х годах после прочтения романа «Город ночи» (City of Night, 1963) Ажона Речи (Jobn Rechy), повествующего о путешествиях молодого хастлера по Америке (ibid: хxi): «Однажды ночью я смотрел "Полуночные колокола" Орсона Уэллса... и я подумал, что пьесы "Генрих IV" на самом деле являются уличной историей. Я также знал это толстого парня по имени Боб, который всегда напоминал мне Фальстафа и был без ума от мальчиковхастлеров. После этого ярешил соединить две истории» (“One night I was watching Orson Welles's Chimes At Midnight... and I thought that the Henry IV plays were really a street story. I also knew this fat guy, named Bob, who had always reminded me of Falstaff and who was crazy about hustler boys. It was then that I decided to combine the two stories"; цит. по: Lyons, 1994: 233).

В фильме персонаж по имени Боб Пиджин (Уильям Ричерт / William Richert), главарь банды, напоминает и своим поведением, и своей судьбой шекспировского Ажона Фальстафа. После того, как Скотт отворачивается от своих старых друзей, Боб умирает от сердечного приступа.

В работе Г. Ван Сента можно найти целый ряд сцен, содержащие шекспировские аллюзии и цитаты. Например, эпизод, когда Боб (Фальстаф) с Баддом (шекспировский судья Роберт Шэллоу) откуда-то возвращаются и по дороге вспоминают прошлое, а члены банды, увидев их с крыши, оповещают об их прибытии всю округу. Боб дословно повторяет известные слова Фальстафа "We have heard the chimes at midnight..." (III, 2; в пер. П. А. Каншина: «Аа, не раз слушали куранты по ночам...» (Шекспир, 2002); в пер. Вл. Э. Морица и М. А. Кузмина: «Аа, приходилось нам слышать, как бьет полночь...» (Шекспир, 1937: 447); в пер. Е. Н. Бируковой: «Аа, частенько мне 
приходилось слышать, как бьет полночь...» (Шекспир, 1959: 188)). Именно из этой фразы шекспировского «жирного плута» позаимствовал название для своего фильма О. Уэллс.

Вторая сцена, отсылающая к хроникам Шекспира, - эпизод, когда Скотт предупреждает Боба, что, когда-то ему исполнится 21 год и он получит наследство отца, он перестанет вести такой образ жизни. Точно также и принц Хэл предупреждает Фальстафа, что когда-то изменится и прекратит с ним общаться:

Третий пример - эпизод, в котором Скотт и Майк отнимают награбленное у Боба точно также, как шутки ради поступают принц Хэл и Нед Пойнс с Фальстафом и его друзьями у Шекспира и Уэллса. Как и Фальстаф, Боб затем откровенно врет о внезапно напавших на них гангстерах, а Майк его высмеивает и выводит на чистую воду. Таким образом, фильм пронизан шекспировскими аллюзиями, точными и неточными цитатами из его исторических хроник. Причем, как уже отмечали некоторые исследователи, Г. Ван Сент иногда демонстрирует, что он делает это не напрямую, а через уэллсовское прочтение шекспировских пьес (ср., например, сцену похорон Фальстафа у Уэллса и Боба у Ван Сента) (см., например: Arthur, Liebler, 1998; Howlett, 2000; переработанный версия этой работы: Howlett, 2002; Barnaby, 2004; Protic, 2013).

В финале фильма Скотт, получивший состояние умершего отца, отвергает пришедших в ресторан Боба и своих бывших приятелей: “I don't know you, old man. Please leave me alone". 5 Также и молодой король Генрих решительно дает понять Фальстафу и его товарищам, что теперь все изменилось и им следует держаться от него подальше. Но есть и некоторые различия. В картине Ван Сента Скотт признается, что любил Боба даже больше отца, но теперь вообще не хочет иметь дело с бывшими друзьями, пока он сам не изменится вспять (“And although I love you more dearly thanmydeadfather, Ihavetoturnaway. Now that I have, and until I change back, don't come near me.”). У Шекспира же король все же жалует им содержание, а в случае их исправления к лучшему они имеют шанс получить должность:

Старик, с тобой я незнаком. Покайся!

Седины вовсе не к лицу шутам.

Мне долго снился человек такой -

Раздувшийся от пьянства, старый, грубый,

Но я проснулся, и тот сон мне мерзок.

Впредь о душе заботься, не о теле.

Обжорство брось: знай, пред тобой могила

Зияет - поглотить тебя готова.

Аурацкой шуткой мне не отвечай.

Не думай, что такой же я, как прежде.

Известно богу - скоро мир увидит,

Что я от прошлого навек отрекся

И отрекусь от всех, с кем знался раньше.

Когда услышишь, что я вновь таков,

Как прежде, приходи ко мне и будешь

Моим руководителем в распутстве.

Ао той поры тебя я изгоняю,

Как всех прогнал, кто совращал меня.

Под страхом смерти вам запрещено

Теперь к особе нашей приближаться

На десять миль. Вам средства к жизни дам, 
Чтобы нужда на зло вас не толкала;

И, если вы исправитесь, дадим

Вам должность в меру ваших сил и знаний.

(V, 5; пер. Е. Н. Бируковой; Шекспир, 1959: 242-243)

Интересно, что некоторые руководители New Line Studio первоначально выступали за то, чтобы столь многочисленные отсылки к Шекспиру были вырезаны, но иностранные дистрибьютеры выступили против этой идеи (Gus Van Sant ..., 1993: xxxviii). Безусловно, шекспировский контекст добавляет фильму философской глубины (конечно, если вы знакомы с творчеством Уэлсса и/ли Шекспира). Как заметил известный кинокритик Роджер Эберт (Roger Ebert), сравнивший Майка с Раскольниковым Ф. М. Аостоевского, «это фильм о жизни двух особенных молодых людей и о том, как они проживают свои жизни» (“...this is a movie about two particular young men, and how they pass their lives"; Ebert, 1991: Электронный ресурс). По его мнению, режиссер отсылками к Шекспиру и Аостоевскому подчеркивает идею о том, что человеческая жизнь нелепа и смешна, а серьезное может в любой момент превратится в абсурдное.

В совместном интервью с Р. Фениксом, опубликованном в ноябрьском номере журнала Interview за 1991 г., К. Ривз признался, что сыгранная роль многое открыла ему в жизни: «Я так много открыл для себя, играя этого парня. Настоящие люди. Мое воображение. Трактовка Гаса. Шекспир. Это было сильно! И это было просто безгранично...» (“...I was introduced to so many elements through the guy I was playing. Real people. My imagination. Gus's interpretation. Shakespeare. It was rich! And it was just bottomless...”; цит. по: My Own Private Idaho, 2011: Электронный ресурс; см. русский перевод: Журнал «Интервью»... : Электронный ресурс). Актер также заметил, что между его героем и шекспировским принцем есть разница. У Шекспира Хэл дабы избежать наказания отца собирает народ в войско, чтобы навести порядок в стране. В результате все довольны: народ получает довольствие, дворяне показывают свою лояльность власти. Более того, он стал в итоге хорошим королем. Скотту же люди не особо интересны, он себе на уме, в нем нет особого благородства (My Own Private Idaho, 2011: Электронный ресурс).

P. Феникс отметил, что не был уверен, что в фильме удастся совместить «пародийный шекспировский материал» (“mock Shakespeare stuff”) и "художественно-документальный уличный материал» (“docudrama street stuff”). Поэтому они приложили усилия, чтобы между ними не было стилистически резких переходов (ibid).

На вопрос, сыграл бы он что-либо из Шекспира, Ривз ответил, что поучаствовал бы вместе с Фениксом, например, в постановке пьес «Сон в летнюю ночь» или «Ромео и Ажульетта», на что Ривер пошутил, что сыграл бы Ажульетту. К сожалению, сыграть Шекспира удалось впоследствии только Ривзу, поскольку его друг и коллега погиб от передозировки наркотиками в 1993 г. К. Ривз же действительно сыграл дона Хуана в фильме «Много шума из ничего» (Much Ado About Notbing) режиссера Кеннета Браны 1993 г., а также Гамлета на сцене Театрального центра Манитобы (в настоящее время - Королевский театральный центр Манитобы / Royal Manitoba Theatre Centre, Виннипег, Канада) в 1995 г. Ради роли принца Аатского он даже отказался от участия в съемках сиквела боевика «Скорость» (Speed, 1994), который был очень успешным в прокате и получил две премии «Оскар». Несмотря на скепсис многих критиков и поклонников, его игра в спектакле имела довольно большой успех и получила в основном положительные отзывы (см., например: Slayen, 1995; Slayen: Электронный 
pecypc; Most Excellent Prince, 1995; Most Excellent Prince: Электронный pecypc; Beard: Электронный ресурс).

На наш взгляд, если бы режиссер сосредоточился на изображении исключительно национального колорита (жизнь портлендских бродяг, американские машины, придорожные кафе, бесконечные шоссе Айдахо и т. А.), то фильм бы больше был похож (с некоторыми, конечно, оговорками) на роуд-муви. Но картина «разбавляется» и әлементами глобального (самолеты, Италия, которую так любил описывать Шекспир). Что касается шекспировского текста, то сложно однозначно трактовать его как проявление исключительно глобального или национального ${ }^{6}$. С одной стороны, шекспировский пласт добавляет общечеловеческие идеи и их можно трактовать как проявление глобального (global Shakespeare). С другой стороны, поскольку, как уже было сказано выше, Г. Ван Сент все же в большей степени отсылает зрителя к «Фальстафу» О. Уэллса, которого все же чаще называют легендой классического голливудского кино, несмотря на его сложные отношения с «Фабрикой грез».

\section{«ИЗОБРАЖАЯ ЖЕРТВУ К. С. СЕРЕБРЕННИКОВА}

8 июня 2006 г. вышел в прокат художественный фильм «Изображая жертву» режиссера К. С. Серебренникова. Авторы сценария (по собственной одноименной пьесе) - братья Олег и Владимир Пресняковы. В 2003 г. К. С. Серебренников поставил по их произведению спектакль на сцене МХАТ им. А. П. Чехова, а спустя несколько лет предложил Пресняковым его экранизировать.

По сюжету молодой человек по имени Валя (Ю. А. Чурсин) устраивается работать в милицию в качестве статиста, изображающего «жертв преступлений» во время видеосъемок следственных экспериментов. Валентин живет вместе с матерью (М. Г. Голуб), с которой находится в не самых лучших отношениях. То ли во сне, то ли в бреду к нему часто является его умерший отец в кителе морского офицера. Родной брат его отца, Петр (Ф. В. Аобронравов), явно неравнодушен к его матери. У Вали есть девушка по имени Ольга (Е. С. Морозова), которая мечтает, что он рано или поздно возьмет ее в жены. Аядя Петр пытается наладить с ним отношения, однако тщетно. Напротив, он натыкается на очень колкие и обидные высказывания в свой адрес. В одном из снов умерший отец намекает Вале, что умер он не своей смертью, и что дядя и его мать в этом замешаны ${ }^{7}$. В итоге герой во время празднования своей официальной помолвки с Олей кормит всех присутствующих японским блюдом фугу, зная о том, что оно может стать ядом, если приготовлено неправильно. Таким экзотическим способом герой отправляет на тот свет мать, дядю и свою девушку. Фильм заканчивается тем, что Валя хладнокровно рассказывает о случившимся своим бывшим коллегам, но уже в качестве подозреваемого.

Перед нами разворачивается жизненная ситуация, внешне очень напоминающая «Гамлета» Шекспира: Валя (Гамлет) находится в непростых взаимоотношениях с матерью и дядей (Гертруда и Клавдий). Отношения с Олей (Офелия) также очень сложные: девушка постоянно впадает в истерики, поскольку он никак не хочет официально взять ее в жены. Вдобавок ко всему во сне к нему постоянно является Призрак отца.

Образ Вали здесь во многом символизирует молодое российское поколение, детство которого пришлось на переломные 1980-е и 1990-е годы. Этот постсоветский Валя-Гамлет инфантилен, бездушен, циничен и, видимо, не очень понимает смысл своей жизни. Хотя, быть может, «шекспировские аллюзии тут - скорее постмодернистское смехачество, чем осмысленный парафраз» (Корецкий, 2007: Электронный ресурс), од- 
нако нам представляется, что история российского Анти-Гамлета ${ }^{8}$ начала XXI в. вплетена в классическую сюжетную конструкцию далеко не случайно. Это только еще более усиливает ощущение трагичности человеческой жизни в контексте современной России ${ }^{9}$.

Кинокритики чаще всего сравнивали Валю с персонажами русской литературы, героями отечественных кинофильмов, а также деятелями истории нашей страны. Например, автор одной из рецензий на портале «КиноПоиск» назвал героя фильма «лишним героем нашего времени» (Малов-кино, 2012: Электронный ресурс), отсылая к роману М. Ю. Аермонтова «Герой нашего времени», повести И. С. Тургенева «Аневник лишнего человека» и литературному типу классической русской литературы (см.: Манн, 1967). Тем самым он, на наш взгляд, подчеркнул широкое распространение подобных Вале молодых людей в современной России. А. К. Савельев увидел в антигерое фильма К. С. Серебренникова черты Ивана из «Курьера» К. Г. Шахназарова (1986): «Про родство Вали с принцем Гамлетом думать не очень интересно. Но вот кому Валя прямой родственник, так это шахназаровскому курьеру Ивану. Вернее, он и есть Иван, которому пришлось родиться двадцать лет спустя и пристраиваться к жизни в наши счастливые дни» (цит. по: «Сеансу» отвечают: Изображая жертву, 2006: Электронный ресурс). П. Черноморский провел параллели между Валей и Печориным, а также декабристами и советскими семидесятниками, которые выросли в период хрущевской оттепели, пережили период брежневской реакции, а затем с развалом СССР не смогли найти себя: «Авторы “Изображая жертву” первыми в наше время заговорили о том, что в стране действительно есть потерянное поколение» (там же). Наконец, П. В. Кузнецов сравнил Валю с Гамлетом, но Гамлетом именно русским, причем новой формации: «...главное, здесь наконец-таки получился старый новый герой - очередной русский Гамлет мытищинского района, идиот, юродивый, - точнее, сумевший органически притвориться таковым» (там же).

В фильме колорит отечественной действительности (летнее кафе с платным туалетом-будкой, бассейн, повседневная работа правоохранительных органов и т. д.) разбавляется упоминаниями других культур, главным образом японской (например, рыба фугу, палочки хаси, которыми ест Валя, женщина в кимоно в ресторане японской кухни ( $\Lambda$. М. Ахеджакова)). В предисловии к изданию сборника пьес братьев Пресняковых, опубликованном еще до выхода фильма на экраны, Серебренников отметил следующее: «Я ставил “Изображая жертву” дважды - в России и в Америке, с американцами. Зрители на разных сторонах Земли смеялись в одних и тех же местах, в одних и тех же местах затихали, создавая ту самую знаменитую театральную тишину, когда слышно, как пролетает муха, даже если никаких мух нет и в помине... Они братья - может быть, первые, кто пишет не про нас для них, а просто про нас. Их тексты не нуждаются в специальной транксрипции, им не требуются пояснительные сноски - они одинаково понятны зрителю в Аиссабоне, Нью-Йорке, Москве... В их пьесах нет ни на йоту привычной для нашей литературы торговли этой пресловутой “загадочной русской душой”, которую все так уже устали разгадывать. Братья, описывают мир, где стерты все границы между Европой и Азией, где измены, предательства и убийства не имеют национальной принадлежности так же, как и забегаловки "Макдоналдс" с их улыбчивыми менеджерами. <...> В этом мире полно отчаянья и почти нет никакой надежды. Аа и на что надеяться? Один страх сковывает персонажей пресняковского мира, страх — “что это все не кончится никогда”...» (Серебренников, 2005: 8-9). 
K. С. Серебренников показал, с нашей точки зрения, Анти-Гамлета нашей эпохи, при этом национальная составляющая у Вали все же присутствует, хотя и не четко выраженная (возможно, именно поэтому большинство критиков охарактеризовали его путем сопоставления с примерами из отечественной культуры). Однако представляется, что режиссер и сценаристы поставили перед собой цель показать, что проблемы, которые поднимаются в фильме, во много характерны не только для России, но и для других стран современного мира. И шекспировские мотивы (а они практически отсутствуют в первой версии пьесы Пресняковых), возможно, были добавлены именно с этой целью.

\section{ЗАКАЮЧЕНИЕ}

Исходя из вышесказанного и подводя некоторые итоги нашего исследования, отметим, что в некоторых фильмах различные аллюзии на произведения того или иного всемирно известного писателя, художника, композитора и т. А., другие прямые или косвенные отсылки к его наследию могут оказывать на зрителя влияние как на национальном уровне (чаще всего посредством построения различных аналогий с известными в той или иной степени для представителей данной культуры феноменами, являющимися примерами национальной рецепции творчества данного автора), так и на глобальном (наднациональном) уровне (путем обращения напрямую к этому автору как яркому и широко известному представителю всемирной культуры).

То есть в случае с Шекспиром режиссеры, используя его наследие, в какой-то степени становятся и его соавторами, вступая в диалог не только с «Великим Бардом», но и с другими «голосами», которые предложили свое видение шекспировского творчества ${ }^{10}$. Эти «голоса» в свою очередь могут быть известны как узкому кругу специалистов, так и большему числу носителей какой-либо культуры, а иногда могут выходить и за рамки национального тезауруса. К этим «голосам» режиссеры и актеры добавляют свои собственные, которые также ретранслируют элементы «тезауруса Шекспира».

Известность и статус режиссера, как считают некоторые теоретики кино, обычно строятся на «трех китах»: высокий уровень технической подготовленности (профессионализм), узнаваемый стиль, а также способность мастерски отобрать материал и показать его так, чтобы сюжет и конфликт фильма вызвал отклик у зрителя (Harrison, 2017: 12) ${ }^{11}$.Создатели фильмов включают в свои картины различные «связующие нити», добавляют интертекстуальные переклички, поскольку они помогаютих творческим идеям и посылупройти сквозь мембрану культурных тезаурусов зрителей и пробудитьинтерес аудитории.

Таким образом, большое количество «шекспировских фильмов» и кинокартин с отсылками к Шекспиру можно объяснить высокой поливалентностью его сюжетов, мотивов и образов. Именно это позволяет использовать их в различных контекстах Аля достижения «эффекта узнаваемости», повышения уровня их культурно-эстетического содержания и т. п. Шекспир как глобальный культурный феномен, а также различные национальные традиции рецепции его наследия являются неиссякаемым источником для творческих идей режиссеров и сценаристов.

В данной статье мы наметили некоторые ориентиры для дальнейшего изучения темы «Шекспир в отечественном кино». Представляется, что изучение влияния шекспировского творчества на кинематограф России и других стран в сложном полилоге национального и глобального может открыть новые горизонты для более глубокого 
понимания происходящих культурных трансформаций и их воздействия на человека в современном мире.

\section{ПРИМЕЧАНИЯ}

1 Этот результат стал для нас несколько неожиданным, поскольку обычно в большинстве источников на втором месте указывается трагедия «Ромео и Ажульетта». См., например, статистику Стивена Фолоуза (StephenFollows): <Follows>, 2014: Электронный ресурс. Интересно, что еще совсем недавно первым фильмом, снятым по Шекспиру, считалась короткометражка «Король Ажон» 1899 г. (реж. Уолтер Феффер Аандо / Walter Pfeffer Dando и создатель одного из первых киносъемочных аппаратов Уильям К.. . Аиксон / William K. L. Dickson), то теперь в базе можно найти данные о «Макбете», снятом в 1898 г. (в главной роли - сэр Ажонстон Форбс-Робертсон / Johnston Forbes-Robertson). См.: Macbeth (1898): Электронный ресурс.

2 Различные современные концепции «всемирной литературы» и их критика представлены, к примеру, в следующих статьях, сборниках и монографиях: Moretti, 2000, 2003; Damrosch, 2003; DebatingWorldLiterature, 2004; Pizer, 2006; Thomsen, 2008; Tanoukhi, 2008.

3 Парадокс «равной ценности» описан в концепции тезаурусных сфер, предложенной Вл. А. Ауковым (Ауков, 2014). См. также: Свалов, 2015, 2016.

4 Заболевание нервной системы, для которого характерны приступы внезапной сонливости и засыпания, иногда сопровождающиеся галлюцинациями, утрата мышечного тонуса, кратковременная парализованность тела и другие симптомы.

5 Ср. со словами молодого короля Генриха V в хронике Шекспира: "Iknowtheenot, oldman. Falltothyprayers." См.: Shakespeare, 1994: 331.

6 Заметим также, что в саундтреке фильма звучит песня Мадонны Cherish, в которой также есть шекспировские аллюзии. См., например, нашу работу: Гайдин, 2014.

7 Отметим, что в тексте пьесы, изданном в 2005 г. нет каких-либо реминисценций шекспировской трагедии о принце Аатском, т. е. нет сцен, когда к Вале во сне приходит умерший при странных обстоятельствах отец, нет мотива предавших отца матери и дяди и др. (см.: Братья Пресняковы, 2005). В другой версии, которую можно найти в Интернете (рискнем предположить, что этот вариант создан на основе сценария фильма) все перечисленные выше шекспировские аллюзии уже есть. Причем Призрак отца Вали говорит о сговоре своего брата и жены, замысливших избавится от него, довольно ясно: «Меня отправила в дорогу // Жена моя... (щепчет) и брат мой...» (Братья Пресняковы: Электронный ресурс). Однако в фильме вся ситуация представлена в более завуалированной форме.

8 О нашем понимании феномена «Анти-Гамлет» см.: Гайдин, 2008, 2011.

${ }^{9}$ См. более подробно в нашей статье: Гайдин, 2013: 176-177.

10 См., например, работу Кита Харрисона (Keith Harrison) о специфике диалогизма в работах кинорежиссеров, обратившихся к творчеству Шекспира, в свете идей М. М. Бахтина: Harrison, 2017.

11 См., например, работы американского кинокритика и теоретика авторского кино Эндрю Сарриса (Andrew Sarris): Sarris, 1962-1963, 1968, 1977.

\section{СПИСОК АИТЕРАТУРЫ}

Братья Пресняковы. (2005) Изображая жертву (Playing the Victim) // Братья Пресняковы. The best : пьесы. М. : Эксмо. 352 с. С. 11-82.

Братья Пресняковы. Изображая жертву (Playing the Victim) (пьеса) [Электронный pecypc] // ModernLib.Ru. URL: http://modernlib.ru/books/presnyakov_vladimir/izobrazhaya_zhertvu_pesa/read [архивировано в WaybackMachine] (дата обращения: $\overline{15} .10 .2017)$.

Виппер, Ю. Б. (1983) Вступительные замечания // История всемирной литературы : в 9 томах / АН СССР; Ин-т мировой лит. им. А. М. Горького. М. : Наука. Т. 1. С. 5-12.

Гайдин, Б. Н. (2008) «Анти-Гамлет» у И. С. Тургенева и Т. Стоппарда // Знание. Понимание. Умение. № 3. С. 231-235. 
Гайдин, Б. Н. (2011) «Анти-Гамлет» Т. Стоппарда // Шекспировские чтения 2006 / Науч. совет «История мировой культуры» РАН ; [гл. ред. А. В. Бартошевич]; [отв. реА., сост. И. С. Приходько]. М. : Наука. С. 209-216.

Гайдин, Б. Н. (2013) Образ Гамлета на отечественном экране второй половины XX - начала XXI века // Знание. Понимание. Умение. №4. С. 170-182.

Гайдин, Б. Н. (2014) Шекспир в современной популярной музыке [Электронный ресурс] // Информационный гуманитарный портал «Знание. Понимание. Умение». №5 (сентябрь - октябрь). URL: http://zpu-journal.ru/e-zpu/2014/5/Gaydin_Shakespeare-Contemporary-Music/ [apхивировано в WaybackMachine] (дата обращения: 15.10.2017).

Гайдин, Б. Н. (2014) Шекспиризация в современном кинематографе // Научные труды Московского гуманитарного университета. № 10. С. 44-71.

Журнах «Интервью», ноябрь 1991 / Р. Феникс, К. Ривз, П. Пауэл (корр.), Аж. Сайкс (корр.) [Электронный ресурс] // Русский сайт Ривера Феникса. URL: http://www.river-phoenix.narod.ru/publications/interviews/interview_11_1991_ru.htm [архивировано в WaybackMachine] (дата обращения: 15.10.2017).

Иванова, $\Lambda$. А. (2015) Понятие «мировая литература» в сравнительном литературоведении Германии // Вестник Новгородского государственного университета им. Ярослава Мудрого. № 4-1 (87). C. 61-64.

Корецкий, В. (2007) Поле брани [Электронный ресурс]// Сеанс. 3 марта. URL: http://seance. $\mathrm{ru} / \mathrm{blog} /$ pole-brani/ [архивировано в WaybackMachine] (дата обращения: 15.10.2017).

Иуков, Вл. А. (2007) Всемирная литература // Новая Российская Энциклопедия : в 12 т. / редкол.: А. А. Некипелов, В. И. Аанилов-Аанильян и др. Т. 4 (1): Винчестер - Гамбург. М. : ООО «Изд-во “Энциклопедия"»; ИА «Инфра-М». 480 с. С. 268-269.

Ауков, Вл. А. (2008) Мировая литература в контексте культуры: новые подходы к исследованию // Вестник Вятского государственного университета. № 1. С. 64-69.

Ауков, Вл. А. (2009) Всемирная литература [Электронный ресурс]// Электронная энциклопедия «Мир Шекспира». URL: http://world-shake.ru/ru/Encyclopaedia/3683.html [архивировано в WaybackMachine] (дата обращения: 9.10.2017).

Иуков, Вл. А. (2014) Концепция тезаурусных сфер // Знание. Понимание. Умение. № 1. C. 307-326.

Малов-кино. (2012) Здравствуй, мальчик-раздолбай! [Электронный ресурс] // КиноПоиск. 7 сентября. URL: http://kinopoisk.ru/user/2153925/comment/1607990/ [архивировано в Wayback Machine] (дата обращения: 6.10.2017).

Манн, Ю. В. (1967) «Аишний человек»// Краткая литературная энциклопедия / гл. ред. А. А. Сурков. М. : Советская энциклопедия. Т. 4: Аакшин - Мураново. 1024 стб. Стб. 400-402.

Неупокоева, И. Г. (1978) Всемирная литература // Краткая литературная энциклопедия. М. : Советская энциклопедия. Т. 9: Аббасзадэ - Яхутль. Стб. 201-210.

Свалов, А. Н. (2015) О тезаурусных сферах. К развитию концепции [Электронный ресурс]// Информационный гуманитарный портал «Знание. Понимание. Умение». №6 (ноябрь - декабрь). С. 5-14. URL: http://zpu-journal.ru/e-zpu/2015/6/Svalov_Thesaurus Spheres/[архивировано в WaybackMachine] (дата обращения: 10.10.2017).

Свалов, А. Н. (2016) Тезаурусные сферы: новые подходы // Знание. Понимание. Умение. №3. C. 157-163. DOI: 10.17805/zpu.2016.3.13

«Сеансу» отвечают... Изображая жертву. (2006) [Электронный ресурс] // Сеанс. № 29-30. URL: http://seance.ru/n/29-30/filmyi/izobrazhaya-zhertvu-2/izobrazhaya-zhertvu-3/ [архивировано в WaybackMachine] (дата обращения: 15.10.2017).

Серебренников, К. С. (2005) Про родственников // Братья Пресняковы. The best : пьесы. М. : Эксмо. 352 с. С. 5-10.

Черепенникова, М. С. (2010) К 260-летнему юбилею со дня рождения И.-В. Гёте (1749-1832). Роль Гёте во всемирной литературе // Филология и человек. № 2. С. 99-104. 
Шекспир, В. (1937) Король Генрих IV. Часть вторая / пер. Вл. Э. Морица, М. А. Кузмина // Шекспир В. Полн. собр. соч. : в 8 т. / под ред. А. А. Смирнова. М. ; $\Lambda$. : Academia. Т. 3. 681 с. C. 367-512.

Шекспир, У. (1959) Генрих IV. Часть вторая / пер. Е. Н. Бируковой // Шекспир У. Полн. собр. соч. : в 8 т. М. : Искусство. Т. 4.650 с. С. 119-247.

Шекспир, У. (2002) Генрих IV / пер. П. А. Каншина. СПб. : Кристалл. 283, [2] с.

Allen, J. (2012) TIFF 2012: 10 Movies that Got at Little Help from the Festival [Электронный реcypc]// Macleans.ca. September 5. URL: http://www.macleans.ca/culture/movies/tiff-2012-10-movies-that-got-at-little-help-from-the-festival/ [архивировано в WaybackMachine] (дата обращения: 10.10.2017).

Annuario del cinema italiano \& audiovisivi. (2010) Rome : Centro studi di cultura, promozione e diffusione del cinema.

Arthur, P., Liebler, N. C. (1998) Kings of the Road: My Own Private Idabo and the Traversal of Welles, Shakespeare, and Liminality // Post Script: Essays in Film and the Humanities. Vol. 17. No. 2. P. 26-38.

Barnaby, A. (2004) Imitation as Originality in Gus van Sant's My Own Private Idabo // Almost Shakespeare: Reinventing His Works for Cinema and Television / ed. by J. R. Keller, L. Stratyner. Jefferson, NC ; London : McFarland \& Co. vi, 197 p. P. 22-41.

Beard, Ch. To Thine Ownself Be Excellent [Электронный ресурс]// Canadian Adaptations of Shakespeare Project. University of Guelph. URL: http://www.canadianshakespeares.ca/essays/ reeves.cfm [архивировано в WaybackMachine] (дата обращения: 15.10.2017).

Bohlman, Ph. V. (2002) World Music: A Very Short Introduction. Oxford : Oxford University Press. xvi, $177 \mathrm{p}$.

Burnett, M. (2007) Filming Shakespeare in the Global Marketplace. Basingstoke ; New York : Palgrave Macmillan. xi, $227 \mathrm{p}$. $324 \mathrm{p}$.

Damrosch, D. (2003) What Is World Literature? Princeton, NJ : Princeton University Press. xiii,

Debating World Literature (2004) / ed. by Ch. Prendergast. London ; New York : Verso. xiii, 353 p.

Dobson, M. (1992) The Making of the National Poet: Shakespeare, Adaptation and Authorship, 1660-1769. Oxford : Clarendon Press. viii, 266 p.

Dudley, A. (2004) An Atlas of World Cinema // The Journal of Cinema and Media. Vol. 45. No. 2. P. 9-23.

Dudley, A. (2006) An Atlas of World Cinema // Remapping World Cinema: Identity, Culture and Politics in Film / ed. by S. Dennison, Song Hwee Lim. London : Wallflower Press. xi, 203 p. P. 19-29.

Ebert, R. (1991) My Own Private Idaho // Chicago Sun-Times. October 18. URL: http://www. rogerebert.com/reviews/my-own-private-idaho-1991 [архивировано в WaybackMachine] (дата обращения: 15.10.2017).

Egoyan, A., Balfour, I. (2004) Introduction // Subtitles: On the Foreignness of Film / ed. by A. Egoyan, I. Balfour. Cambridge, MA ; London : MIT Press. 532 p. P. 3-12.

$<$ Follows, S.> (2014) How Many Movies Based on Shakespeare Plays Are There? [Электронный pecypc]// Stephen Follows - Film Industry Data and Education. April 14. URL: https://stephenfollows.com/movies-based-on-shakespeare-plays/ [архивировано в WaybackMachine] (дата обращения: 6.10.2017).

Global Shakespeare (2012) / ed. by J. M. González, R. Wilson, C. Bellis. Alicante : Universidad de Alicante. 418 p. (Alicante Journal of English Studies / Revista Alicantina de Estudios Ingleses, no. 25).

Guinness World Records 2017. (2016) London: Guinness World Records Limited. 255 p. P. 176.

Gus Van Sant: Swimming against the Current : An Interview (1993) / G. Fuller (corr.), G. Van Sant // Van Sant G. Even Cowgirls Get the Blues ; My Own Private Idaho. London : Faber \& Faber. lv, 199 p. P. vii-liii.

Harrison, K. (2017) Shakespeare, Bakhtin, and Film: A Dialogic Lens. Cham : Palgrave Macmillan. $267 \mathrm{p}$. 
Hill, J. (2000) General Introduction // World Cinema: Critical Approaches / ed. by J. Hill, P. Ch. Gibson ; consultant editors: R. Dyer, E. Ann Kaplan, P. Willemen. Oxford ; New York : Oxford University Press. xv, 234 p. P. xiv-xv.

Howlett, K. M. (2000) Utopian Revisioning of Falstaff's Tavern World: Orson Welles's Chimes at Midnight and Gus Van Sant's My Own Private Idabo // Framing Shakespeare on Film. Athens : Ohio University Press. xvii, 255 p. P. 149-177.

Howlett, K. M. (2002) Utopian Revisioning of Falstaff's Tavern World: Orson Welles's Chimes at Midnight and Gus Van Sant's My Own Private Idabo // The Reel Shakespeare: Alternative Cinema and Theory / ed. by L. S. Starks, C. Lehmann. Madison, NJ ; Teaneck : Fairleigh Dickinson University Press ; London: Associated University Presses. 298 p. P. 165-188.

Huang, A. (2013) Global Shakespeares as Methodology // Shakespeare: Journal of the British Shakespeare Association. Vol. 9. Issue 3. P. 273-290.

Lopes, D. (2010) Global Cinema, World Cinema // E-compós. Vol. 13. No. 2. P. 1-16. Lynch, K. (2014) William Shakespeare Turns 450 - Ten Startling Great Bard-Themed World Records [Электронный ресурс] // Guinness World Records. April 23. URL: http://www.guinnessworldrecords.com/news/2014/4/william-shakespeare-turns-450-ten-startling-great-bard-themedworld-records-56900/ [архивировано в WaybackMachine] (дата обращения: 6.10.2017).

Lyons, D. (1994) Independent Visions: A Critical Introduction to Recent Independent American Film. New York : Ballantine Books. xiv, 337 p.

Macbeth (1898) [Электронный ресурс]// IMDb. URL: http://www.imdb.com/title/tt2398191/ [архивировано в WaybackMachine] (дата обращения: 6.10.2017).

Moretti, F. (2000) Conjectures on World Literature // New Left Review. No. 1. P. 54-68.

Moretti, F. (2003) More Conjectures// New Left Review. No. 20. P. 73-81.

Most Excellent Prince (1995) // The Sunday Times. January 22.

Most Excellent Prince [Электронный ресурс]// Whoa Is (Not) Me. Defending Keanu Reeves. URL: http://www.whoaisnotme.net/articles/1995_0122_mos.htm [архивировано в WaybackMachine] (дата обращения: 15.10.2017).

Murray, K. (2013) Shakespeare and World Cinema: A Critical Overview // Literature Compass. Vol. 10. Issue 4. P. 369-382.

My Own Private Idaho (2011) / R. Phoenix, K. Reeves P. Powell (corr.), G. Sikes (corr.) [Электронный ресурс]// Interview. September 28. URL: https://www.interviewmagazine.com/ film/myown-private-idaho [архивировано в WaybackMachine] (дата обращения: 15.10.2017).

Native Shakespeares: Indigenous Appropriations on a Global Stage (2008) / ed. by C. Dionne, P. Kapadia. Aldershot ; Burlington, VT : Ashgate. ix, 247 p.

Nesbit, E. (2012) Beautiful Stories From Shakespeare : eBook. [Lanham, MD] : Start Publishing.

Nowell-Smith, G. (1997) General Introduction // The Oxford History of World Cinema / ed. by G. Nowell-Smith. Oxford: Oxford University Press. xxii, 824 p. P. xix-xxii.

Orkin, M. (2005) Local Shakespeares: Proximations and Power. London; New York : Routledge. $\mathrm{x}, 220 \mathrm{p}$.

Pearson, R. E. (2004) Heritage, Humanism, Populism: The Representation of Shakespeare in Contemporary British Television // Janespotting and Beyond: British Heritage Retrovisions since the Mid-1990s / ed. by E. Voigts-Virchow. Tübingen : Gunter Narr. 212 p.

Pizer, J. D. (2006) The Idea of World Literature: History and Pedagogical Practice. Baton Rouge, LA : Louisiana State University Press. x, 190 p.

Protic, N. (2013) "There is the Bawdy? Falstaffian Politics in Gus Van Sant's My Own Private Idabo // Literature Film Quarterly. Vol. 41. No. 3. P. 184-196.

Research topic: Folk and world music [Электронный ресурс]// UiO Universitetet i Oslo — Det humanistiske fakultet. URL: http://www.hf.uio.no/imv/english/research/subjects/folk-world-music/ [архивировано в WaybackMachine] (дата обращения: 10.10.2017).

$<$ Results for "Hamlet" $>$ [Электронный ресурc]// IMDb. URL: http://www.imdb.com/find?q=Ham-

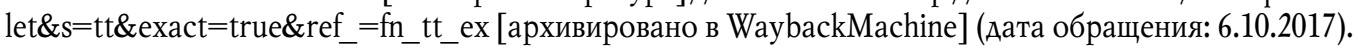


$<$ Results for "Macbeth" $>$ [Электронный ресурс]// IMDb. URL: http://www.imdb.com/find?q= Macbeth\&s=tt\&exact=true\&ref_=fn_tt_ex [архивировано в WaybackMachine] (дата обращения: 6.10.2017).

$<$ Results for "Romeo and Juliet" $>$ [Электронный ресурc] // IMDb. URL: http://www.imdb. $\mathrm{com} /$ find?q $=$ Romeo $\% 20 \mathrm{and} \% 20 \mathrm{Juliet \& s}=\mathrm{tt} \&$ exact $=$ true\&ref_=fn_tt_ex [архивировано в Wayback Machine] (дата обращения: 6.10.2017).

Sarris, A. (1962-1963) Notes on the Auteur Theory in 1962 // Film Culture. No. 27. P. 1-8.

Sarris, A. (1968) The American Cinema: Directors and Directions 1929-1968. New York : Dutton. 383 p.

Sarris, A. (1977) The Auteur Theory Revisited // American Film. Vol. 2. No. 9. P. 49-53.

Shakespeare and National Culture (1997) / ed. by J. J. Joughin. Manchester ; New York : Manchester University Press. ix, $351 \mathrm{p}$.

Shakespeare on the Global Stage: Performance and Festivity in the Olympic Year (2015) / ed. by P. Prescott, E. Sullivan. London ; New York : Bloomsbury Arden Shakespeare, an imprint of Bloomsbury Publishing. xvii, $356 \mathrm{p}$.

Shakespeare, W. (1994) The Complete Oxford Shakespeare : in 3 vols. / ed. by S. Wells, G. Taylor. Oxford ; New York : Oxford University Press. Vol. 1: Histories. xliii, 452 p.

Shakespeare: World Views (1996) / ed. by H. Kerr, R. Eaden, M. Mitton. Newark, DE : University of Delaware Press ; London ; Cranbury, NJ : Associated University Presses. 258 p.

Slayen, S. (1995) Keanu Shines as Hamlet // What! February - March. Slayen, S. Keanu Shines as Hamlet [Электронный ресурс]// Whoa Is (Not) Me. Defending Keanu Reeves. URL: http://www.whoaisnotme.net/articles/1995_02xx_kea2.htm [архивировано в WaybackMachine] (дата обращения: 15.10.2017).

Tanoukhi, N. (2008) The Scale of World Literature// New Literary History. Vol. 39. No. 3. P. 599-617.

The Guinness Book of Records 1999 (1998) / ed. by M. Young. [S.l.]: Guinness World Records Ltd. 336 p.

Thomsen, M. R. (2008) Mapping World Literature: International Canonization and Transnational Literatures. London; New York : Continuum. 170 p.

Thurman, Ch. (2016) South African Essays on 'Universal' Shakespeare. Abingdon, Oxon : Routledge. xxi, $208 \mathrm{p}$.

Vipper, Y. B. (1985) National Literary History in History of World Literature: Theoretical Principles of Treatment// New Literary History. Vol. 16. No. 3. P. 545-558.

William Shakespeare [Электронный ресурc] // IMDb. URL: http://www.imdb.com/name/ nm0000636/ [архивировано в WaybackMachine] (дата обращения: 6.10.2017).

World-Wide Shakespeares: Local Appropriations in Film and Performance (2005) / ed. by S. Massai. London; New York : Routledge. xii, 199 p.

Аата поступления: 15.10.2017 2.

Гайдин Борис Николаевич - кандидат философских наук, начальник Научно-исследовательского отдела цифровых технологий Института фундаментальных и прикладных исследований Московского гуманитарного университета, член-корреспондент Международной академии наук (IAS, Инсбрук). Адрес: 111395, Россия, г. Москва, ул. Юности, 5, корп. 6. Тел.: +7 (499) 374-59-30. Эл. aApec: bngaydin@mosgu.ru

Gaydin Boris Nikolaevich, Candidate of Philosophy, Head of the Research Department of Digital Technologies, Institute of Fundamental and Applied Studies, Moscow University for the Humanities; Associate Member, International Academy of Science (IAS, Innsbruck). Postal address: Bldg. 6, 5 Yunosti St., Moscow, Russian Federation, 111395. Tel.: +7 (499) 374-59-30. E-mail: bngaydin@ mosgu.ru

\section{Аля изитирования:}

Гайдин Б. Н. Шекспир в кино: национальное и глобальное [Электронный ресурс] // Горизонты гуманитарного знания. 2017. №5. URL: http://journals.mosgu.ru/ggz/article/view/606 (дата обращения: АА.мм.гггг). DOI 10.17805/ggz.2017.5.9. 